\title{
LINGUAGEM, DISCURSO E DOMINAÇÃO EM LÉVINAS
}

\author{
LANGAGE, DISCOURS ET DOMINATION EN LÉVINAS
}

Luiz Fernando Pires Dias*

\begin{abstract}
RESUMO
Este artigo examina a utilização do discurso como instrumento de poder, dominação e violência, através da perspectiva de Emanuel Lévinas, filósofo lituano, que buscou um novo sentido para o humano, fora dos domínios do ser, pensando a ética como Filosofia Primeira. O estudo está alicerçado nas análises que o filósofo da Alteridade desenvolveu em relação a dois fenômenos político-históricos: a gênese da ideologia hitlerista e a ambiguidade retórica ocorrida no processo de desestalinização da antiga União Soviética. Suas considerações constituem importantes subsídios à compreensão do cenário de intolerância, polarização de ideias e consequente ausência de diálogo que hoje vivenciamos. Refletimos, também, sobre a questão da linguagem em Lévinas, concepção desenvolvida através de uma crítica contundente à primazia da ontologia no pensamento ocidental, que privilegiou a síntese redutora e totalizante da realidade, suprimindo o espaço à alteridade. Lévinas procurou seus referenciais na ética, no encontro humano, na nudez do rosto que, como palavra vivente, investe o homem da responsabilidade pelo seu próximo.
\end{abstract}

PALAVRAS-CHAVE: Discurso. Dominação. Ética. Lévinas. Linguagem.

\section{RÉSUMÉ}

Cet article examine l'utilisation du discours en tant qu'instrument de pouvoir, de domination et de violence à travers la perspective d'Emmanuel Lévinas, philosophe lituanien qui a cherché un nouveau sens pour l'humain en dehors des domaines de l'être, en considérant l'éthique comme philosophie première. L'étude est fondée sur les analyses développées par le philosophe d'Altérité à propos de deux phénomènes politico-historiques: la genèse de l'idéologie hitlerienne et l'ambiguïté rhétorique qui s'est produite dans le processus de déstalinisation de l'ex-Union Soviétique. Leurs considérations constituent des subventions importantes pour la compréhension du scénario d'intolérance, polarisation des idées et l'absence de dialogue que nous vivons aujourd'hui. Nous réfléchissons également à la question du langage chez Lévinas, conception développée à travers une critique sévère à la primauté de l'ontologie dans la pensée occidentale, qui privilégiait la synthèse réductrice et totalisante de la réalité, supprimant l'espace à l'altérité. Lévinas a cherché ses références dans l'éthique, dans la rencontre humaine, dans la nudité du visage qui, en tant que parole vivante, confère à l'homme une responsabilité envers son prochain.

MOTS-CLÉS: Discours. Domination. Éthique. Lévinas. Langage.

\footnotetext{
* Graduação em Ciências Contábeis e Filosofia pela PUC Minas. Mestre em Ciências da Religião. E-mail: 1.ferna@ig.com.br.
} 


\section{INTRODUÇÃO}

O contexto atual de crise e intolerância encontra-se entrelaçado a inúmeras narrativas de cunho político, econômico, religioso, ou mesmo científico, com pretensões à totalidade, fazendo com que seja necessária e premente a reflexão sobre o emprego do discurso como instrumento de dominação e violência contra o outro. Os diversos fundamentalismos atuais, que atentam contra a democracia e contra os direitos humanos, muitas vezes são interpretados erroneamente como movimentos antagônicos ao Niilismo, mas, na realidade, são figuras correlatas a este, ou, até mesmo, deste tornam-se subprodutos, constituindo uma questão imperiosa a uma Filosofia que almeje estar uníssona às necessidades de seu tempo.

Preocupações em relação ao discurso e à sua utilização com finalidades que extrapolam o campo da comunicação e da partilha de informações, enveredando-se na esfera da manipulação e da doutrinação, a serviço de interesses pessoais ou de determinados grupos, estiveram presentes, de maneira recorrente, na reflexão filosófica de Emmanuel Lévinas que, com destemor e lucidez, abordou o discurso em uma direção diametralmente oposta ao percurso desenvolvido pela determinação conceitual da ontologia, ao estabelecer uma peculiar conexão entre a linguagem e a trama ética.

Ao falarmos de ética, convém já de início destacar uma breve diferenciação entre o significado que é atribuído a tal vocábulo na tradição ocidental e o sentido singular que esta palavra alcançou na produção filosófica levinasiana. A chamada ética ocidental é considerada como uma ciência da conduta, vinculada profundamente à ontologia, à questão do ser, com o ethos se submetendo ao logos, como esclarece Ribeiro Junior (2008, p. 268):

A ética grega, ao se autoproclamar como discurso ou metalinguagem sobre o agir, dobrou-se à pretensão da ontologia de estabelecê-la como derivada ou ser considerada um de seus ramos. Nesse sentido, a própria ética reconhece que seu sentido vem fora dela mesma, no ser.

O pensamento levinasiano ultrapassa a ideia de ética como mera disciplina da filosofia ou como uma legislação formal acerca dos atos que decretam o comportamento virtuoso a partir de um saber ou de um conhecimento:

Nós chamamos ética uma relação entre termos, na qual um e outro não são nem unidos por uma síntese do entendimento, nem pela relação de sujeito ao objeto e na qual, entretanto, um pesa, ou importa, ou é significante ao outro, e aqui eles estão 
ligados por uma intriga que o saber não saberia nem esgotar, nem desenredar. (LÉVINAS, 2010, p. 314, tradução nossa) ${ }^{1}$.

O filósofo lituano postula uma ressignificação da ética, pensando-a como uma estrutura preexistente, como um ordenamento primordial que fundamenta a própria subjetividade humana. Trata-se de uma perspectiva que considera a ética antecedente até mesmo à minha relação com o mundo (KOVAC, 1993, p. 179). Portanto, na concepção de Lévinas, não é o exercício racional que vai instituir a ética, mas é a ética que se torna o fator determinante e fundador de uma racionalidade que não exclui e nem reduz o Outro a mero objeto de tematização. A trama ética está coadunada à relação original de um Eu imbuído de uma responsabilidade inalienável pelo seu próximo, cuja alteridade lhe concerne, relação sem a qual, segundo o filósofo, nenhum discurso tem legitimidade.

O foco do presente artigo é investigar com Lévinas a utilização do discurso como instrumento de poder e violência, buscando em sua filosofia uma alternativa a essa preocupante questão. Nesse intuito, iniciaremos demarcando, de forma concisa, a crítica que o filósofo direcionou à pretensão de totalidade presente na ontologia. Em seguida, apresentaremos a análise produzida por Lévinas concernente a dois fenômenos políticohistóricos por ele vivenciados: a gênese da ideologia hitlerista e a ambiguidade da retórica utilizada no processo de desestalinização da antiga URSS. A ênfase recairá sobre a ideologia nazista, cujo discurso configurou-se como símbolo maior do totalitarismo e da violência. Finalizando, buscaremos demarcar o estatuto axiológico conferido à dimensão da linguagem na filosofia da alteridade de Emmanuel Lévinas.

\section{A VIOLÊNCIA DA TEMATIZAÇÃO}

Situamos a crítica direcionada por Lévinas à linguagem de matriz logocêntrica, prevalente no transcurso histórico da Filosofia, na interseção dos seguintes aspectos: a constante tentativa perpetrada pelo pensamento ocidental de adequação do Outro ao Mesmo, homogeneizando a realidade e confinando-a em uma esfera de finitude; a presunção de síntese última e inequívoca atribuída ao discurso filosófico do Ocidente, que se desenvolveu sob a égide da totalidade, representada pela rigidez do conceito determinativo; a primazia

\footnotetext{
${ }^{1}$ Nous appelons éthique une relation entre des termes où l'un et l'autre ne sont unis ni par une synthèse de l'entendement ni par la relation de sujet à objet et où cependant l'un pèse ou importe ou est signifiant à l'autre, où ils sont liés par une intrigue que le savoir ne saurait ni épuiser ni démêler.
} 
incondicional atribuída ao saber e ao conhecimento em nossa cultura, com a inteligibilidade se dando a partir do desvelamento do ser.

De acordo com Lévinas, a tradição ocidental adotou a apreensão e a tematização como formas de assimilação e expressão da realidade. Ocorre que, conforme o filósofo, essa forma de compreensão do fenômeno gera como consequência o movimento de captura e neutralização do objeto de conhecimento. Dessa maneira, o conhecimento passa a ser estruturado como uma apropriação, em uma tentativa da síntese racional de toda existência, convertendo-se em um pensamento com pretensões absolutas que, enquanto saber, almeja internalizar toda a exterioridade à consciência que a visa, anulando-a e impedindo a diferença:

\begin{abstract}
O evento ontológico que se opera por meio da filosofia consiste em suprimir ou em transmutar a alteridade de todo Outro, em universalizar a imanência do Mesmo ou a Liberdade, em apagar as fronteiras, em expulsar a violência do Ser. O Eu conhecedor é o receptáculo de tal transmutação. Ele é o Mesmo por excelência. Quando o Outro entra no horizonte do conhecimento ele já renuncia à alteridade. O retorno eterno do idealismo não resulta de uma predileção caprichosa dos filósofos em relação à teoria do conhecimento. Ele repousa sobre sólidas razões que fundamentam o privilégio do Mesmo em relação ao Outro. (LÉVINAS, 2006, p. 97, tradução nossa $)^{2}$.
\end{abstract}

Em relação a Outrem, os mecanismos do conhecimento, centralizados no Eu, provocam a redução do homem a mero objeto, suprimindo a sua humanidade, determinando um processo de instrumentalização do ser humano: "Conhecer é perceber, apreender um objeto - ainda que se trate de um homem ou grupo de homens - capturar uma coisa." (LÉVINAS, 1976, p. 25, tradução nossa) ${ }^{3}$. Desse modo, o pensamento adequa-se ao caráter limitante e totalizante do conceito, coadunado à apreensão e à síntese: "Enquanto compreender, o pensamento comporta um prender, uma apreensão, uma assimilação do que é aprendido e uma posse. O 'apreender' do compreender não é puramente metafórico." (LÉVINAS, 1991, p. 134, tradução nossa) ${ }^{4}$.

Na nossa tradição filosófica, o conhecimento, edificado no ser, foi alçado ao cume incontestável da inteligibilidade. A primazia conferida ao conhecimento, sendo esse entendido

\footnotetext{
${ }^{2}$ L'événement ontologique qui s'accomplit par la philosophie, consiste à supprimer ou à transmuer l'altérité de tout Autre, à universaliser l'immanence du Même ou la Liberté, à effacer les frontières, à expulser la violence de l'Être. Le Moi connaissant est le creuset d'une telle transmutation. Il est le Même par excellence. Quand l'Autre entre dans l'horizon de la connaissance, il renonce déjà à l'altérité. Le retour éternel de l'idéalisme ne résulte pas d'une prédilection capricieuse des philosophes pour la théorie de la connaissance. Il repose sur de solides raisons qui fondent le privilège du Même par rapport à l'Autre.

${ }^{3}$ Connaître, c'est percevoir , saisir un objet - et fût-il homme ou groupe d'hommes - saisir une chose.

${ }^{4}$ En tant qu'apprendre, la pensée comporte un prendre, une saisie, une prise sur ce qui est appris et une possession. Le «saisir» de l'apprendre n'est pas purement métaphorique.
} 
como domínio do que se conhece, indica a postura desenvolvida no Ocidente, por inspiração helênica, a via do logos, consubstanciada na lógica do verbo "ver". Tal estruturação é narrada por Lévinas da seguinte forma:

\begin{abstract}
A esfera da inteligibilidade - do razoável - na qual se mantém a vida cotidiana e mesmo a tradição de nosso pensamento filosófico e científico caracteriza-se pela visão. A estrutura do ver, tendo o visto por objeto ou por tema - estrutura dita intencional - se encontra em todos os modos da sensibilidade acessando as coisas; ela se encontra no acesso intelectual aos estados-de-coisas ou às relações entre coisas e, aparentemente, também na frequentação dos seres humanos entre si, entre seres que se falam e dos quais se diz que se veem. Assim, anuncia-se a prioridade do conhecer, em que se entrelaça tudo o que chamamos pensamento, ou inteligência, ou espírito, ou simplesmente psiquismo. (LÉVINAS, 1991, p. 165, tradução nossa) ${ }^{5}$.
\end{abstract}

Com a inteligibilidade fundada sobre os alicerces do ver e do conhecer, o Eu adquiriu um papel hegemônico, fazendo com que a filosofia se exprimisse prioritariamente na primeira pessoa, caracterizando-se, segundo Lévinas, por aspectos predominantemente egológicos, a começar por Sócrates:

É a lição de Sócrates, que somente deixa ao mestre o exercício de maiêutica: todo o ensinamento introduzido na alma, aí já se encontrava. A identificação do Eu, - a maravilhosa autarquia do eu - é a prova natural dessa transmutação do Outro em Mesmo. Toda filosofia é uma egologia, para empregar um neologismo husserliano. (LÉVINAS, 2010, p. 232-233, tradução nossa) ${ }^{6}$.

O primado do Mesmo, aspecto que floresceu e imperou nos grandes sistemas filosóficos, fez com que a história da filosofia ocidental perpetrasse uma verdadeira destruição da transcendência (LÉVINAS, 2004, p. 95). Na passagem abaixo, Lévinas descreve o contexto redutor do Outro, desenvolvido nos domínios do “conhecer", no qual o Outro já não é tido como Outro, ficando restrito à esfera do Mesmo, tendo a imanência como corolário:

Enquanto saber, o pensamento é a maneira pela qual uma exterioridade se encontra no interior de uma consciência que não cessa de se identificar, sem ter de recorrer para isso a nenhum signo distintivo e é Eu: o Mesmo. O saber é uma relação do

\footnotetext{
${ }^{5}$ La sphére de l'intelligibilité - du sensé - , dans laquelle se maintient la vie quotidienne et même la tradition de notre pensée philosophique et scientifique, se caractérise par la vision. La structure du voir ayant le vu pour objet ou pour thème - structure dite intentionnelle - se retrouve dans tous les modes de la sensibilité accédant aux choses; elle se retrouve dans l'accession intelectuelle aux états-de-choses ou aux relations entre choses et apparemment aussi dans la fréquentation des êtres humains entre eux, entre êtres qui se parlent et dont on dit qu'ils se voient. Ainsi s'annonce la priorité du connaître où se noue tout ce que nous appelons pensée ou intelligence ou sprit ou tout simplement psychisme.

${ }^{6}$ C'est la leçon de Socrate, qui ne laisse au maître que l'exercise de la maïeutique: tout enseignement introduit dans l'âme y fut déjà. L'identification du Moi, - le merveilleuse autarcie du moi - est le creuset naturel de cette transmutation de l'Autre en Même. Toute philosophie est une égologie pour employer un néologisme husserlien.
} 
Mesmo com o Outro, em que o Outro se reduz ao Mesmo e se despoja de sua singularidade, na qual o pensamento se refere ao outro, mas aqui o outro não é mais outro enquanto tal, aqui ele já é o próprio, já meu. Ele está a partir de então sem segredos ou aberto à pesquisa, isto é, mundo. Ele é imanência. (LÉVINAS, 1996, p.12-13, tradução nossa) ${ }^{7}$.

A aspiração ao conhecimento absoluto presente na tradição filosófica estende-se também ao discurso proveniente desta. A Filosofia e a ciência constituem conhecimentos que almejam dizer a realidade do ser, ambicionam um discurso inconteste em todos os seus postulados, sendo, portanto, saberes com pretensões à pronúncia definitiva: “O discurso filosófico do Ocidente reivindica a amplitude de um englobamento ou de uma compreensão última. Obriga todo discurso a justificar-se diante da filosofia.” (LÉVINAS, 2004, p. 94, tradução nossa) ${ }^{8}$.

No âmbito da ontologia, as palavras não se limitam ao intento de apenas se constituir em signos que correspondam às coisas, indo além, na busca da instauração de instância última portadora da verdade, na qual o ser se manifesta. A tematização atrela-se indubitavelmente ao ser, restringindo toda realidade a esse domínio. Tal situação tem sua origem na identificação obrigatória entre pensamento e realidade, entre o pensamento e o que é pensado: "Essa dignidade de último e real discurso recai sobre a filosofia ocidental em virtude da coincidência rigorosa entre o pensamento em que a filosofia se mantém e a ideia da realidade em que este pensamento pensa." (LÉVINAS, 2004, p. 94, tradução nossa) ${ }^{9}$.

A crítica levinasiana à ontologia tem como alvo central e recorrente a ontologia de Heidegger, filósofo que, acima de qualquer outro, voltou seu pensamento para a questão do ser, buscando a restauração do sentido do ser e a versatilidade dessa palavra. Heidegger estabelece a abertura do ser como a instância derradeira da compreensão, implicando absorção do Outro pelo Mesmo:

Em suma, as teses conhecidas da filosofia heideggeriana: a precedência do Ser em relação ao ente, da ontologia em relação à metafísica, acabam por afirmar uma

\footnotetext{
${ }^{7}$ En tant que savoir, la pensée est la façon dont une extériorité se retrouve à l'intérieur d'une conscience qui ne cesse de s'identifier, sans avoir à recourir pour cela à aucun signe distinctif et est Moi: le Même. Le savoir est une relation du Même avec l'Autre où l'Autre se réduit au Même et se dépouille de son étrangeté, où la pensée se rapporte à l'autre mais où l'autre n'est plus autre en tant que tel où il est déjà le propre, déjà mien. Il est désormais sans secrets ou ouvert à la recherche, c'est-à-dire monde. Il est immanence.

${ }^{8}$ Le discours philosophique de l'Occident revendique l'amplitude d'un englobement ou d'une compréhension ultime. Il astreint tout autre discours à se justifier devant la philosophie.

${ }^{9}$ Cette dignité d'ultime et royal discours, revient à la philosophie occidentale en vertu de la coïncidence rigoureuse entre la pensée où la philosophie se tient et l'idée de la réalité où cette pensée pense.
} 
tradição onde o Mesmo domina o Outro, onde a liberdade - mesmo que idêntica à razão - precede a justiça. (LÉVINAS, 2010, p. 237, tradução nossa) ${ }^{10}$.

Na perspectiva de Lévinas, a centralidade do conhecimento, fundamentada na abertura do ser, abre espaço à violência:

\begin{abstract}
A compreensão, ao se reportar ao ente na abertura do ser, confere-lhe significação a partir do ser. Nesse sentido, ela não o invoca, apenas o nomeia. E, assim, comete a seu respeito uma violência e uma negação. Negação parcial que é violência. E essa parcialidade descreve-se no fato de que o ente, sem desaparecer, se encontra em meu poder. A negação parcial, que é a violência, nega a independência do ente: ele depende de mim. A posse é o modo pelo qual um ente, embora existindo, é parcialmente negado. (LÉVINAS, 1991, p. 20, tradução nossa) ${ }^{11}$.
\end{abstract}

Ocorre que o real e a sua expressão não são, obrigatoriamente, equivalentes, não se podendo atribuir ao logos enquanto discurso o status de própria expressão da realidade. Ao expressar o mundo através de conceitos rígidos, na pretensão de se dizer o ser, frequentemente comete-se violência, pois entram em jogo os conceitos de veracidade e de validade, extrapolando o próprio campo do diálogo, pois, muitas vezes, quem fala já defende uma posição, buscando estender seu conceito individual, num impulso à universalização, caracterizando a utilização da linguagem, no âmbito da ontologia, como instrumento de poder e de controle sobre o outro, conforme contundente elaboração de Fabri (1997, p. 13): “A ontologia traduz, no fundo, uma filosofia do poder e da violência, ou ainda, a dominação imperialista, a tirania e o poder do Estado."

Tal conjuntura converte-se em solo fértil para dogmatismos e fundamentalismos ${ }^{12}$ amplamente disseminados nos tempos atuais, seja na política, na religião, na economia, e até mesmo na ciência, conforme apontado por Lévinas: "Uma espécie de neocientismo e de neopositivismo domina o pensamento ocidental. Ele se estende aos saberes tendo o homem

\footnotetext{
${ }^{10}$ En somme, les thèses connues de la philosophie heideggerienne: la précellence de l'Être par rapport à l'étant, de l'ontologie par rapport à la métaphysique, achèvent d'affirmer une tradition où le Même domine l'Autre, où la liberté - fût-elle identique à la raison - précède la justice.

${ }^{11}$ La compréhension, en se rapportant à l'étant dans l'ouverture de l'être, lui trouve une signification à partir de l'être. Dans ce sens, elle ne l'invoque pas, mais le nomme seulement. Et ainsi elle accomplit à son égard une violence et une négation. Négation partielle qui est violence. Et cette partiellité se décrit dans le fait que l'étant, sans disparaître, se trouve en mon pouvoir. La négation partielle qu'est la violence nie l'indépendance de l'étant: il est à moi. La possession est le mode selon lequel un étant, tout en existant, est partiellement nié.

${ }^{12}$ Nesse texto utilizamos a palavra "fundamentalismo" no mesmo horizonte de sentido apontado por Boff, na seguinte definição: "Fundamentalismo representa a atitude daquele que confere caráter absoluto ao seu ponto de vista." (BOFF, 2002, p. 25).
} 
por objeto, e às próprias ideologias [...]" (LÉVINAS, 2004, p. 22, tradução nossa) ${ }^{13}$. Nesse aspecto, vivenciamos um quadro de crescimento de narrativas radicais, tanto nas ideologias, como em sociedades cada vez mais polarizadas e menos propensas ao diálogo, que buscam a globalização de suas doutrinas, ou supostas "verdades", representando um sério risco à dignidade da pessoa humana, ao hostilizar e marginalizar as diferenças, configurando-se como um desafio de dimensões superlativas à nossa reflexão.

\section{IDEOLOGIA E VIOLÊNCIA}

Em seu transcurso de vida, Lévinas se deparou com doutrinas e discursos totalizantes e violentos, com destaque para o nacional-socialismo, uma das ideologias mais radicais e perniciosas do Século XX. Os princípios ideológicos do nazismo foram estabelecidos com base no pressuposto da superioridade germânica, que contemplava e autorizava o extermínio sistemático de inimigos e opositores, suscitando uma violência injustificável. Em um de seus primeiros textos, Quelques réflexions sur la philosophie del'hitlérisme, publicado na revista Esprit, de 1934, o filósofo já refletia sobre essa ameaça, que então prenunciava-se e que tragicamente se concretizou, em uma análise que constitui substancial fonte de estudo à compreensão de nossa realidade contemporânea.

O artigo se inicia com a contundente assertiva: "a filosofia de Hitler é primária" (LÉVINAS, 1997, p. 7, tradução nossa) ${ }^{14}$, com a qual o autor retira da ideologia nazista a distinção e deferência usualmente conferidas aos sistemas filosóficos. No entanto, intitular a ideologia hitlerista de filosofia já a estabelece como objeto passível de análise filosófica. Nesse aspecto, faz-se importante ressaltar que o propósito de Lévinas não foi a exposição de uma suposta filosofia contida nos preceitos nazistas, mas sim a produção de um exame crítico do fenômeno sócio-histórico do nazismo, pautado no método fenomenológico (ABENSOUR, 1997, p. 28). Dizer que a filosofia de Hitler é primária sugere, também, a existência nessa “filosofia" de um nível mais profundo e primitivo de visão de mundo, carregado de pulsões incivilizadas, esquivas às percepções refinadas do pensamento ocidental:

Não se trata, portanto, e essa é a tese da íntegra do texto que já se anuncia, de alguma "ausência" de racionalidade, mas, justamente, da presença de um estilo

\footnotetext{
${ }^{13}$ Une espèce de néo-scientisme et de néo-positivisme domine la pensée occidentale. Il s'étend aux savoirs ayant l'homme pour objet, il s'étend aux idéologies elles-mêmes [...].

${ }^{14}$ La philosophie d'Hitler est primaire.
} 
muito preciso de racionalidade arcaica, primeva e poderosa, que se disfarça em sua "fraseologia miserável" e à qual os espíritos cultivados não estão acostumados e, muito menos, afeitos, e nem ao menos habilitados a reconhecer e a interpretar, dado que se apresenta como antípoda seja do "esprit de géometrie", seja do "esprit de finesse”. (SOUZA, 2012, p.18).

Lévinas (1997, p. 07, tradução nossa) constata que "mais que um contágio ou uma


considerados extremamente perigosos por Lévinas, pois emergem da obscuridade, dissimulados em uma pseudofilosofia que ultrapassa a própria ideologia manifesta, colocando-se em contraposição às concepções e às bases sobre as quais fora estabelecida a cultura ocidental, tendo a liberdade humana como um de seus princípios capitais. Tal concepção de liberdade desenvolvida em nossa civilização outorgou ao homem a possibilidade de refazer seu trajeto a cada instante, sobrepujando a própria irreversibilidade do tempo: "A verdadeira liberdade, o verdadeiro começo exigiria um verdadeiro presente que, sempre no apogeu de um destino, a recomece eternamente.” (LÉVINAS, 1997, p. 09, tradução nossa $)^{16}$. Nessa perspectiva, sempre foi considerado um dos fatores decisivos na definição do homem o tempo que ainda lhe resta.

As visões de mundo trazidas pela tradição do judaísmo, pela mensagem de salvação do cristianismo e pelas teorias do liberalismo apresentavam a liberdade como um horizonte de inspiração comum. Mesmo o pensamento desenvolvido por Marx, em que pese uma nova valoração atribuída aos aspectos materiais, não apresentava um caráter radical, nem definitivo, no que diz respeito à vinculação existente entre espírito e matéria, uma vez que "tomar consciência de sua situação social é para Marx se libertar do fatalismo que ela comporta" (LÉVINAS, 1997, p. 15, tradução nossa) ${ }^{17}$.

A ideologia nazista, expressa por Lévinas como "filosofia do hitlerismo", estabeleceu um pensamento que tomou como ponto de partida os atributos corpóreos, uma doutrina direcionada à imanência, ao privilegiar, de forma cabal, a consanguinidade e os fatores materiais da existência humana, divergindo do modelo antropológico hegemônico desenvolvido pela tradição ocidental, que invariavelmente privilegiou a razão em relação ao corpo, chegando a atribuir a este, certo grau de descaso e estranhamento:

\footnotetext{
${ }^{15}$ Plus qu'une contagion ou une folie, l'hitlérisme est un réveil des sentiments élémentaires.

${ }^{16}$ La vraie liberté, le vrai commencement exigerait un vrai présent qui, toujours à l'apogée d'une destinée, la recommence éternellement.

17 Prendre conscience de sa situation sociale, c'est pour Marx lui-même s'affranchir du fatalisme qu'elle comporte.
} 
É o sentimento da eterna estranheza do corpo em relação a nós que alimentou o Cristianismo, bem como o liberalismo moderno. Foi tal sentimento que persistiu através de todas as variações da ética e a despeito do declínio sofrido pelo ideal ascético desde o Renascimento. Se os materialistas confundiam o eu com o corpo, era ao preço de uma negação pura e simples do espírito. Eles localizavam o corpo na natureza, eles não lhe concediam um status excepcional no Universo. (LÉVINAS, 1997, p. 16, tradução nossa) ${ }^{18}$.

A cultura ocidental desenvolveu uma concepção de homem não circunscrita às limitações somáticas. Considerar carne e sangue os fatores centrais da existência humana implica uma nova noção de homem, cuja essência já não se situa em um domínio de liberdade, mas na consciência do seu atrelamento inexorável à dimensão corpórea. $\mathrm{O}$ hitlerismo pautou-se pela valorização do corpo e dos aspectos biológicos do ser humano, inaugurando uma ótica na qual esses elementos se tornaram capitais na delimitação do homem. $\mathrm{O}$ atrelamento definitivo às suas características corporais e hereditárias produz como consequência a revogação da liberdade até então atribuída ao ser humano, impondo-lhe um confinamento à genética, ao passado e às suas origens: “A essência do homem já não está na liberdade e sim em uma espécie de agrilhoamento." (LÉVINAS, 1997, p. 19) ${ }^{19}$. O hitlerismo apoiou-se em um plano teórico que negou a transcendência e a própria humanidade, conforme afirma Sebbah (2009, p. 200),

\begin{abstract}
Além de negar a transcendência do Infinito em relação à imanência do ser e ao horizonte do mundo - a qual era perceptível através de tentativas feitas, à maneira peculiar de cada um, pelo judaísmo e pelo cristianismo -, o nazismo nega, pelo mesmo movimento, a disposição fundamental de cada si mesmo humano a evadir-se dele mesmo, assim como do mundo. E é assim, nesta negação simultânea das transcendências do Infinito e do si, que ele produz o anonimato sem rosto de uma (in) humanidade de massa.
\end{abstract}

O ameaçador discurso hitlerista, sinalizando uma correlação primária entre o homem e o seu corpo, portador de formas de racismo subjacentes e explícitas, aspirava à universalidade, através da expansão ideológica e da dominação. Consideramos que a seguinte reflexão de Lévinas nos remete ao ponto fulcral da análise sobre a violência característica das ideologias e das narrativas que ambicionam a universalização e o poder:

\footnotetext{
${ }^{18}$ C'est le sentiment de l'éternelle étrangeté du corps par rapport à nous qui a nourri le Christianisme aussi bien que le libéralisme moderne. C'est lui qui a persisté à travers toutes les variations de l'éthique et malgré le déclin subi par l'idéal ascétique depuis la Renaissance. Si les matérialistes confondaient le moi avec le corps, c'était au prix d'une négation pure et simple de l'esprit. Ils plaçaient le corps dans la nature, ils ne lui accordaient pas de rang exceptionnel dans l'Univers.

${ }^{19}$ L'essence de l'homme n'est plus dans la liberté, mais dans une espèce d'enchaînement.
} 
A verdade, por mais que seja minha verdade, no sentido mais forte desse possessivo, deve tender à criação de um mundo novo. Zaratustra não se contenta com a sua transfiguração, ele desce de sua montanha e traz um evangelho. Como a universalidade é compativel com o racismo? Haverá - e está na lógica da inspiração primeira do racismo - uma modificação fundamental da ideia mesma da universalidade. Ela deve dar lugar à ideia de expansão, pois a expansão de uma força apresenta uma estrutura totalmente diferente da propagação de uma ideia. (LÉVINAS, 1997, p. 22, tradução e grifo nossos) ${ }^{20}$.

No questionamento que acima sublinhamos, o filósofo evidencia o paradoxo existente entre a noção de universalidade e o conceito de racismo. Trata-se de uma incompatibilidade intrínseca à própria essência do racismo. Doutrinas de determinismo racial e de apologia de raças envolvem vícios intelectuais e morais ao privilegiarem raças "ditas" superiores, em inevitável detrimento de outros grupos raciais. Diante da pretensão de universalidade, concomitante à impossibilidade de difundir ideologias através da comunhão e do acolhimento de pensamentos, o prenúncio da utilização da força se faz presente, com o estabelecimento de um cenário de dominadores e dominados.

Lévinas, em sua análise, demarca a diferenciação das características e dos itinerários utilizados pela propagação de uma ideia e pela expansão de uma força. A disseminação de uma ideia não fica confinada substancialmente à sua origem, não exigindo um retorno à fonte. A ideia tem como característica principal a autonomia, pois, por mais que se evidencie a assinatura daquele que a transmitiu, recepcioná-la já é compartilhar de sua propriedade, em uma condição de coparticipação: “Aquele que a aceita torna-se seu senhor como aquele que a propõe." (LÉVINAS, 1997, p. 22-23, tradução nossa) ${ }^{21}$. A divulgação de uma ideia desencadeia um processo de equalização do grupo dos que a partilham: "Converter ou persuadir é criar pares.” (LÉVINAS, 1997, p. 23, tradução nossa) ${ }^{22}$.

Já a expansão da força é determinada por um processo bastante distinto. A força atrela-se àquele que a exerce, que detém o seu domínio pleno. A força não se coloca à disposição daqueles nos quais ela é exercida, sendo sua posse exclusiva do agente ativo, seja este um indivíduo, um grupo ou uma sociedade. A força ambiciona tornar refém e subordinar aqueles aos quais ela é dirigida. No caso da expansão de uma força, o âmago da questão não diz respeito apenas à disseminação de uma ideologia, mas da própria expansão como um fim

\footnotetext{
${ }^{20}$ La vérité a beau être ma vérité au plus fort sens de ce possessif - elle doit tendre à la création d'un monde nouveau. Zarathoustra ne se contente pas de sa transfiguration, il descend de sa montagne et apporte un évangile. Comment l'universalité est-elle compatible avec le racisme? Il y aura là - et c'est dans la logique de l'inspiration première du racisme - une modification fondamentale de l'idée même de l'universalité. Elle doit faire place à l'idée d'expansion, car l'expansion d'une force présente une tout autre structure que la propagation d'une idée.

${ }^{21}$ Celui qui l'accepte devient son maître comme celui qui la propose.

${ }^{22}$ Convertir ou persuader, c'est se créer des pairs.
} 
em si mesmo: "Aqui a ordem universal não se estabelece como corolário de expansão ideológica - é esta expansão que constitui a unidade de um mundo de senhores e escravos." (LÉVINAS, 1997, p. 23, tradução nossa) ${ }^{23}$. Tais princípios conduzem, necessariamente, à violência e, em última análise, à guerra, provocando fissuras nos alicerces de nossa cultura ocidental e, principalmente, colocando em risco “[...] a própria humanidade do homem" (LÉVINAS, 1997, p. 24, tradução nossa) ${ }^{24}$.

Através de um Post-scriptum, no ensejo do lançamento da tradução norte-americana de Quelques réflexions sur la philosophie de l'hitlérisme, em 1990, Lévinas ampliou a sua avaliação crítica sobre os sentimentos elementares contidos na ideologia hitlerista, identificando no violento e trágico itinerário nazista a perspectiva de existência de um "Mal Elementar", contra o qual o pensamento ocidental não estava precavido o suficiente, não como o fruto de uma contingência histórica ou de algum desacerto ideológico ocasional, mas como uma probabilidade inerente a um pensamento que se funda no modelo ontológico:

Há neste artigo a convicção de que essa fonte se vincula a uma possibilidade essencial do Mal elementar em que boa lógica pode conduzir e contra a qual a filosofia ocidental não estava suficientemente garantida. Possibilidade que se inscreve na ontologia do Ser, cuidadoso de ser [...] (LÉVINAS, 1997, p. 25, tradução nossa $)^{25}$.

A crítica levinasiana à violência e totalização do discurso não se restringiu à ideologia nazista. Nessa mesma vertente, citaremos, também, o artigo Liberté de Parole, de 1957, no qual o filósofo analisa o processo de desestalinização, que teve como marco decisivo a calculada liberação do discurso, de forma supostamente secreta, do então secretário geral do Partido Comunista da União Soviética Nikita Khrushchev, no $20^{\circ}$ Congresso desse partido (1956), com a exposição da intolerância, brutalidade e abuso de poder ocorridos sob a liderança de Josef Stalin, líder da URSS de 1922 até o ano de sua morte em 1953.

Diante do encadeamento de fatos que se seguiu a essa ruptura com a totalidade vigente, ensejando prenúncios de novas formas de totalitarismo, incluindo o desmentido e as ambiguidades de Khrushchev em relação ao referido discurso, Lévinas vislumbrou a denúncia de uma mistificação como o próprio engendramento de uma nova mistificação, como a gênese

\footnotetext{
${ }^{23}$ Ici l'ordre universel ne s'établit pas comme corollaire d'expansion idéologique - il est cette expansion même qui constitue l'unité d'un monde de maîtres et d'esclaves.

${ }^{24}[\ldots]$ l'humanité même de l'homme.

${ }^{25}$ Il y a dans cet article la conviction que cette source tient à une possibilité essentielle du Mal élémental où bonne logique peut mener et contre laquelle la philosophie occidentale ne s'était pas assez assurée. Possibilité qui s'inscrit dans l'ontologie de l'Être, soucieux d'être [...].
} 
de uma nova ilusão. Para o filósofo, o mais alarmante aspecto desse processo foi a diminuição do crédito atribuído à linguagem, em um patamar abrangente e coletivo:

\begin{abstract}
Não se pode mais acreditar nas palavras, pois não se pode mais falar. Não é que a liberdade de expressão permaneça ainda inconclusa na maior parte da terra ou que os homens se sirvam dela para mentir. Não se pode mais falar, pois ninguém pode começar seu discurso sem testemunhar logo algo distinto disso que foi dito. Psicanálise e sociologia observam os interlocutores. As palavras são sintomas ou superestruturas. De sorte que os gritos e os gestos do acordar fazem parte do pesadelo que deveriam interromper. (LÉVINAS, 1976, p. 309, tradução nossa) ${ }^{26}$.
\end{abstract}

Lévinas considerou a neutralização e o processo de perda de fidedignidade da palavra, presentes no totalitarismo político, como características intrínsecas de um totalitarismo ontológico:

Este infinito de mentira é impotência de romper. O totalitarismo político repousa sobre um totalitarismo ontológico. O ser seria um todo. Ser onde nada acaba e onde nada começa. Nada se opõe a ele e ninguém o julga. Neutro anônimo, universo impessoal, universo sem linguagem. (LÉVINAS, 1976, p. 309-310, tradução nossa $)^{27}$.

Tal situação guarda semelhança com situação vivenciada pelo filósofo no pressentimento e na experiência concreta do hitlerismo, ocasião na qual o quadro totalitário também ensejou a supressão da liberdade do discurso. Em entrevista, ao citar os indicativos que o fizeram perceber a ascensão do Nazismo, Lévinas faz menção à impossibilidade de interlocução: "Não havia mais discurso possível." (LÉVINAS, 2019).

Frente a discursos que aspiram à universalidade, que propõem verdades incontroversas e almejam a expansão de forças e aquisição de poder, sendo, consequentemente, portadores de violência e dominação, Lévinas opõe a socialidade do diálogo, com a palavra sendo tratada como relação ética com Outrem, partindo da significância do rosto do próximo.

\footnotetext{
${ }^{26}$ On ne peut plus croire aux paroles, car on ne peut plus parler. Ce n'est pas que la liberté de parole reste encore inaccomplie sur la plus grande partie de la terre ou que les hommes s'en servent pour mentir. On ne peut plus parler, car personne ne peut commencer son discours sans témoigner aussitôt de toute autre chose que de ce qui se dit. Psychanalyse et sociologie guettent les interlocuteurs. Les mots son des symptômes ou des superstructures. De sorte que les cris e les gestes du réveil font partie du cauchemar qu'ils devaient interrompre.

${ }^{27}$ Cet infini du mensonge est une impuissance de rompre. Le totalitarisme politique repose sur un totalitarisme ontologique. L'être serait un tout. Etre où rien ne finit et où rien ne commence. Rien ne s'oppose à lui et personne ne le juge. Neutre anonyme, univers impersonnel, univers sans langage.
} 


\section{LINGUAGEM ÉTICA}

A decisiva interrogação introduzida por Emmanuel Lévinas em relação à linguagem consistiu em inquirir se a razão, geralmente considerada como condição de possibilidade desta, precede-a necessariamente, ou se antes, a linguagem não estaria alicerçada em uma relação originária, antecedente à compreensão e estruturante da própria razão.

Para o filósofo lituano, a relação com Outrem excede os poderes da compreensão, pois traz consigo um chamamento: "Outrem não é primeiro objeto de compreensão e, depois, interlocutor. As duas relações confundem-se. Dito de outra forma, da compreensão de outrem é inseparável sua invocação. Compreender uma pessoa já é falar-lhe.” (LÉVINAS, 1991, p. 17 , tradução nossa $)^{28}$.

Independente da mensagem explícita ou subjacente ao discurso, o falar é essencialmente relação, sendo a significação do diálogo um elemento inseparável da proximidade, do face a face com Outrem. Tal perspectiva opõe a significação engendrada no âmbito da ética levinasiana, estabelecida na exposição a Outrem, e a significação ontológica, entendida como identificação e tematização do fenômeno (CALIN; SEBBAH, 2002, p. 55).

Em Lévinas, o aspecto primordial da linguagem repousa na relação com o Outro, cujo encontro implica já se apresentar significando, sendo a comunicação inaugurada no trauma da alteridade. Trata-se de um encontro irredutível à representação e que, segundo o filósofo, situa-se no centro da produção de sentido. O encontro humano posiciona-se fora dos domínios do saber e da ontologia, pois não posso encontrar Outrem sem lhe falar, sem externar esse encontro, não havendo um hiato entre pensamento e expressão:

\footnotetext{
A relação com outrem não é, portanto, ontologia. Essa ligação com outrem que não se reduz à representação de outrem, mas à sua invocação, e cuja invocação não é precedida de uma compreensão, nós a chamamos de religião. A essência do discurso é oração. O que distingue o pensamento que visa um objeto de uma vinculação com uma pessoa é que nesta se articula um vocativo: o que é nomeado é, ao mesmo tempo, o que é chamado. (LÉVINAS, 1991, p. 19, tradução nossa) ${ }^{29}$.
}

\footnotetext{
${ }^{28}$ Autrui n'est pas objet de compréhension d'abord et interlocuteur ensuite. Les deux relations se confondent. Autrement dit, de la compréhension d'autrui est inséparable son invocation. Comprendre une personne, c'est déjà lui parler.

${ }^{29}$ La relation avec autrui n'est donc pas ontologie. Ce lien avec autrui qui ne se réduit pas à la représentation d'autrui, mais à son invocation, et où l'invocation n'est pas précédée d'une compréhension, nous l'appelons religion. L'essence du discours est prière. Ce qui distingue la pensée visant un objet d'un lien avec une personne, c'est que dans celui-ci s'articule un vocatif : ce qui est nommé est, en même temps, ce qui est appelé.
} 
Em sua primeira grande obra, Totalité et infini: essai sur l'extériorité, Lévinas postula uma vinculação precípua entre o discurso e a justiça, produzindo a seguinte formulação: "Chamamos justiça ao acolhimento do face a face no discurso. [...] A verdade só se produz no verdadeiro discurso ou na justiça." (LÉVINAS, 2014, p. 67, tradução nossa) ${ }^{30}$. Nesse contexto, o filósofo atrela de forma definitiva a justiça à responsabilidade irremissível e assimétrica em relação ao próximo: “A verdade, portanto, vincula-se à relação social que é a justiça. A Justiça consiste em reconhecer em outrem o meu mestre.” (LÉVINAS, 2014, p. 68, tradução nossa) $)^{31}$.

Trata-se de uma ótica na qual a justiça legitima o discurso, sendo este portador de um significado original determinado pela trama ética, esfera anterior ao próprio logos: “A linguagem é o campo do sentido ético." (FERON, 1992, p. 85, tradução nossa) ${ }^{32}$. Portanto, o discurso, na perspectiva de Lévinas, deve estar pautado em um Dizer precedente ao próprio ser e aos jogos de linguagem, vinculando-se a uma estrutura determinada pela responsabilidade imperativa em relação ao próximo, que transcende a lógica sistêmica de um discurso demarcado apenas pela retórica e pelo conhecimento.

Para Lévinas, o ponto de referência maior da relação humana e consequentemente da linguagem é o rosto, cuja manifestação não pode ser sintetizada pela razão sem a utilização de um expediente redutor, de uma violência. O rosto, na concepção de Lévinas, não pertence à ordem da compreensão e sim ao domínio da ética. Sua significância transcende as delimitações físicas, constituindo um caráter excessivo, que fratura as estruturas cognitivas do pensamento, impossibilitando o seu enquadramento na relação sujeito e objeto:

\begin{abstract}
A nudez do rosto não é o que se oferece a mim porque eu o desvelo - e que, por esse fato, se ofereceria a mim, aos meus poderes, aos meus olhos, às minhas percepções em uma luz que lhe é externa. O rosto se voltou para mim - e é essa a sua nudez. Ele é por si próprio e não por referência a um sistema. (LÉVINAS, 2014, p. 72, tradução nossa $)^{33}$.
\end{abstract}

O rosto e o discurso estão intrinsecamente conectados, pois o primeiro é a condição sine qua non do segundo, levando-se em conta uma conjuntura verdadeiramente ética. A

\footnotetext{
${ }^{30}$ Nous appelons justice cet abord de face, dans le discours. [...] la vérite ne se produit que dans le véritable discours ou dans la justice.

${ }^{31} \mathrm{La}$ vérité se rattache ainsi au rapport social qui est justice. La justice consiste à reconnaître en autrui mon maître.

${ }^{32}$ Le langage est le champ du sens éthique.

${ }^{33}$ La nudité du visage n'est pas ce qui s'offre à moi parce que je le dévoile - et qui, de ce fait, se trouverait offert à moi, à mes pouvoirs, à mes yeux, à mes perceptions dans une lumière extérieure à lui. Le visage s'est tourné vers moi - et c'est cela sa nudité même. Il est par lui-même et non point par référence à un système.
} 
relação autêntica com Outrem é permeada pela situação de sem defesa e de exposição do rosto, que é ao mesmo tempo um convite à violência e, também, a própria interdição ética a essa violência, residindo aí toda a ambiguidade do rosto. O rosto fala, possuindo uma eloquência que comunica para além do conhecimento efetivo, sendo significação irredutível a um contexto, não se deixando transformar em tema forjado na adequação do saber. Conforme o filósofo, o rosto "é o que não se pode tornar um conteúdo que nosso pensamento englobaria; é o incontível, leva-nos além. Eis a razão de o significado do rosto o levar a sair do ser, enquanto correlativo de um saber" (LÉVINAS, 1982, p. 81, tradução nossa) ${ }^{34}$.

Há no rosto um comando de natureza ética, advindo da manifestação de sua fragilidade. Ele é portador de uma pobreza essencial, ostentando a própria incondição humana, pautada pela finitude e pela perene exposição do homem à morte e ao sofrimento. $\mathrm{O}$ apelo decisivo da fragilidade do rosto interpela a minha moral, pois a nudez do rosto me obriga a uma resposta. Nessa perspectiva, sou sempre plenamente responsável, não sendo livre para decidir em relação à suspensão dessa responsabilidade. A primeira palavra do diálogo advém do ato de apropriar-se desse encargo, através da resposta ética originária: "eisme aqui." (LÉVINAS, 1978, p. 226, tradução nossa) ${ }^{35}$.

A nudez do rosto foge aos poderes da tematização, inaugurando um discurso que não se alicerça no conhecimento do interlocutor, mas, antes, fundamenta-se na proximidade de Outrem, que já se expõe como portador de significação, inaugurando de imediato um acontecimento ético. É o trauma inicial do encontro que estabelece a linguagem, com a instauração do sentido se iniciando com a chegada de Outrem, que não é passível de apreensão, ocorrendo uma quebra de paradigma, com o Outro passando a ser a fonte originária da inteligibilidade.

O Outro chega e eloquentemente determina a si próprio, através da nudez de seu rosto, que é inapreensível, ocasionando uma imperiosa reordenação da lógica. Outrem é justamente aquele que se apresenta significando, mesmo antes que qualquer exercício racional do $\mathrm{Eu}$ possa pretender conferir a ele alguma interpretação. Dessa forma, a presença do Outro se faz anacrônica à consciência, pois o rosto é kath'auto, o rosto se autodetermina: "Nós chamamos rosto à autossignificância por excelência." (LÉVINAS, 2010, p. 320, tradução nossa) ${ }^{36}$.

\footnotetext{
${ }^{34}$ Il est ce qui ne peut devenir un contenu, que votre pensée embrasserait; il est l'incontenable, il vous mène audelà. C'est en cela que la signification du visage le fait sortir de l'être en tant que corrélatif d'un savoir.

35 «me voici».

${ }^{36}$ Nous avons appelé visage l'auto-signifiance par excelence.
} 
Portanto, a expressão do rosto difere de todo signo, não se situando em um horizonte de desvelamento e nem na esfera de irracionalidade; ela detém a primazia da significação, que se ancora em uma inteligibilidade anterior a minha própria liberdade, em um domínio em que a violência encontra o seu não lugar. $O$ discurso dominador e a ação violenta ocorrem justamente na falta da relação com o Outro: "Toda violência é fruto de um exercício de poder, que impede que outrem seja outrem.” (PAIVA, 2010, p. 125). A violência direcionada a alguém é, em última análise, um elemento concernente à guerra e às hostilidades diversas. $\mathrm{Na}$ ótica do filósofo lituano, a interdição à violência provém do rosto, não sendo uma oposição antagônica, tendo, ao contrário, uma natureza pacífica:

\begin{abstract}
A face, o rosto, é o fato de que uma realidade me é oposta; oposta não em suas manifestações, mas em sua maneira de ser, se podemos assim dizer, ontologicamente oposta. É o que me resiste por sua oposição e não o que se opõe a mim por sua resistência. Eu quero dizer que essa oposição não se revela colidindo com minha liberdade, é uma oposição anterior a minha liberdade e que a coloca em marcha. (LÉVINAS, 1994, p. 46, tradução nossa) ${ }^{37}$.
\end{abstract}

A violência ocorre quando o impedimento contido no rosto é intencionalmente desconsiderado, quando a individualidade do Outro é ignorada e subjugada. Para o real acatamento a um discurso formulado, sem que se faça necessário o emprego de violência, fazse imperativa a relação face a face com o Outro, cujo rosto é, antes de tudo, mandamento ético, é vestígio do infinito.

É exatamente a noção de vestígio, desenvolvida por Lévinas em relação ao rosto, que possibilita um discurso primordial, fundado em uma relação originária, anterior à síntese racional. A abstração do rosto encontra-se fora da ordem do ser. Na presença do rosto, respondemos a um horizonte de outra categoria, que traduz uma ruptura irrevogável com o ordenamento lógico. Trata-se da significância do vestígio, que significa sem se mostrar, não se deixando transformar em fenômeno. A proximidade do rosto já se traduz em distanciamento. A significância do rosto espelha sempre uma ausência, um passado irrevogável: "O vestígio é a presença daquele que, estritamente falando, nunca esteve lá, daquele que é sempre passado.” (LÉVINAS, 1972, p. 68, tradução nossa) ${ }^{38}$.

\footnotetext{
${ }^{37}$ La face, le visage, est le fait qu'une réalité m'est opposée; opposée non pas dans ses manifestations, mais dans sa manière d'être, si on peut dire, ontologiquement opposée. C'est ce qui me résiste par son opposition, et non pas ce qui s'oppose à moi par sa résistance. Je veux dire que cette opposition ne se révèle pas en heurtant ma liberté, c'est une opposition antérieure à ma liberté et qui la met en marche.

${ }^{38}$ Le trace est la présence de ce qui, à proprement parler, n'a jamais été là, de ce qui est toujours passé.
} 
O rosto constitui uma privilegiada abertura à exterioridade e à transcendência, locus singular onde a palavra Deus alcança seu significado: “O rosto é o lugar da palavra de Deus. Existe a palavra de Deus em outrem, palavra não tematizada.” (LÉVINAS, 1995, p. 114, tradução nossa) ${ }^{39}$. O Deus da tradição judaico-cristã revela-se através de seu vestígio, permanecendo como traço, no infinito de sua ausência. Ir até Ele, antes de buscar um ídolo, é achar-se em seu vestígio. Nesse aspecto, para Lévinas, a própria relação metafísica só é factível enquanto relação ética. O rosto do Outro, que se expõe ao meu olhar sem qualquer ornamentação social, na sua nudez, na sua fragilidade e na sua absoluta ausência de segurança, porta um comando supremo: “Tu não matarás”, eco da palavra do Deus invisível:

\begin{abstract}
Deus - ou a Palavra de Deus - me vem à ideia, concretamente, diante do rosto do outro homem onde eu leio o comando Tu não matarás. A interdição inscrita no rosto não saberia passar por isso que chamamos prova da existência de Deus. Mas é a circunstância em que a palavra Deus toma sentido. (MALKA, 1989, p. 25, tradução nossa $)^{40}$.
\end{abstract}

Portanto, é na relação com o rosto que a ideia de Infinito ganha a sua concretude e se estabelece como um Dizer fundador, que precede toda a experiência e que antecede as próprias palavras, sendo, acima de tudo, o testemunho da responsabilidade pelo próximo. Esse Dizer primordial, estabelecido pela nudez do rosto e pela irredutibilidade da alteridade de Outrem, deve nortear o Dito do discurso. Um Dito que deve movimentar-se, de desdito em desdito, em constante correção inspirada pelo Dizer originário, dimensão mais profunda e primordial da linguagem, que corresponde à própria responsabilidade ética.

\title{
CONSIDERAÇÕES FINAIS
}

Os discursos totalitários pretendem, em última análise, a dissolução das individualidades, negligenciando a singularidade insubstituível das pessoas, perpetrando um aglomerado humano, indiferenciado e disforme, vinculado aos interesses daqueles que os proferem, configurando um cenário que contrasta, radicalmente, com a concretude da exposição da face humana.

\footnotetext{
${ }^{39}$ Le visage est le lieu de la parole de Dieu. Il y a la parole de Dieu en autrui, parole non thématisée.

${ }^{40}$ Dieu - ou la Parole de Dieu - me vient à l'idée, concrètement, devant le visage de l'autre homme où je lis le commandement Tu ne tueras point. L'interdit inscrit sur le visage ne saurait passer pour ce qu'on appelle preuve de l'existence de Dieu. Mais il est la circonstance où le mot Dieu prend sens.
} 
Em sentido oposto, no pensamento de Lévinas, a linguagem sai do logocentrismo em direção ao próximo, constituindo um saber privilegiado, verdadeiro caminho para a justiça: "É a partir da aproximação que a noção mesma de rosto se impõe. E, no rosto, o conhecimento e a manifestação do ser ou a verdade, envolvem-se em uma relação ética." (LÉVINAS, 2010, p. 320 , tradução nossa) ${ }^{41}$. O enfoque de Lévinas permite o vislumbre de um discurso antes do próprio discurso, no qual a palavra estabelecida na intriga ética do encontro humano tem precedência absoluta sobre a argumentação instituída pelo cálculo racional.

O discurso importa menos pelo seu conteúdo informativo, ou pela comunicação de uma ideia, do que pelo fato de dirigir-se a um interlocutor. Ele promove, antes de tudo, uma relação com a exterioridade, com o Outro sendo abordado enquanto Outro, sem os artifícios preestabelecidos da arte da retórica, que podem ofuscar e distorcer a verdade.

A relação irredutível, o face a face do discurso, se esquiva da totalidade e nos remete a uma ordem mais antiga do que a do logos grego: o domínio ético, no qual a espontaneidade da presença de Outrem desestabiliza os meus poderes de sujeito. O apelo do rosto é pura transcendência, é relação com o Infinito, que provoca a ruptura com a totalidade do discurso, com o Outro sendo elevado à dignidade de fonte única e original do sentido, com Outrem sendo considerado como um fim em si mesmo e nunca como um meio para a consecução de algum interesse ou resultado.

\section{REFERÊNCIAS}

ABENSOUR, M. Le mal élémental. In: LÉVINAS, E. 1997. Quelques réflexions sur la philosophie de l'hitlérisme, suivi d'un essai de Miguel Abensour. Paris: Payot \& Rivages, 1997. p. 27-103.

BOFF, Leonardo. Fundamentalismo: a globalização e o futuro da humanidade. Rio de Janeiro: Sextant, 2002.

CALIN, Rodolphe; SEBBAH, François-David. Le vocabulaire de Lévinas. Paris: Ellipses, 2002.

FABRI, Marcelo. Desencantando a ontologia: subjetividade e sentido ético em Levinas. Porto Alegre: EDIPUCRS, 1997.

FERON, Etienne. De l'idée de transcendance à la question du langage: l'itinéraire philosophique d'Emmanuel Levinas. Grenoble: Jérôme Millon, 1992.

\footnotetext{
${ }^{41}$ C'est à partir de l'approche que la notion même du visage s'impose. Et dans le visage la connaissance et la manifestation de l'être ou la vérité, s'engloutissent dans un rapport éthique.
} 
KOVAC, Edvard. L'Intrigue éthique. In: GREISCH, Jean; ROLLAND, Jacques (dir.).

Emmanuel Lévinas: l'éthique comme philosophie première. Paris: Cerf, 1993. p. 177-192.

LÉVINAS, E. Altérité et transcendance. Paris: Fata Morgana, 1995. (Le livre de poche).

LÉVINAS, E. Autrement qu'être ou au-delà de l'essence. Paris: Kluwer Academic, 1978. (Le livre de poche).

LÉVINAS, E. De Dieu qui vient à l’idée. 2. ed. Paris: Vrin, 2004.

LÉVINAS, E. Difficile liberté: essais sur le jadaïsme. 3. ed. Paris: Albin Michel, 1976. (Le livre de poche).

LÉVINAS, E. En découvrant l'existence avec Husserl et Heidegger. 4 ed. Paris: Vrin. LÉVINAS, E. Entre nous: essais sur le penser-à-1'autre. Paris: Grasse, 1991. (Le livre de poche).

LÉVINAS, E. Éthique et infini: dialogues avec Philippe Nemo. Paris: Fayard, 1982. (Le livre de poche).

LÉVINAS, E. Humanisme de l'autre homme. Paris: Fata Morgana, 1972. (Le livre de poche).

LÉVINAS, E. Liberté et commandement. Paris: Fata Morgana, 1994. (Le livre de poche).

LÉVINAS, E. Quelques réflexions sur la philosophie de l'hitlérisme, suivi d'un essai de Miguel Abensour. Paris: Payot \& Rivages, 1997.

LÉVINAS, E. Totalité et infini: essai sur l'extériorité. Paris, Librarie Générale Française, 2014. (Le livre de poche).

LÉVINAS, E. Transcendance et hauteur. In: CHALIER, Catherine; ABENSOUR, Miguel et al. (dir.). Lévinas. Paris, L’herne, 2006. p. $97-112$.

LÉVINAS, E.. Transcendance et intelligibilité. Genève, Labor et Fides, 1996.

LÉVINAS, E. Entrevista. Sodaperaga (France), avec le concours du Ministère de la Culture. Por: François Poirié, Annie Chevallay e Pierre-André Boutang. Disponível em: https://www.youtube.com/watch?v=jIZnjFLpZ_A. Acesso em: 14 abr. 2019.

MALKA, Salomon. Lire Lévinas. 2. ed. Paris: Les Éditions du Cerf, 1989.

PAIVA, Márcio Antônio de. Da ética ao discurso sobre Deus. In: PAIVA, Márcio Antônio de; OLIVEIRA, Ibraim Vitor de et al. Violência e discurso sobre Deus. São Paulo: Paulinas; Belo Horizonte: PUC Minas, 2010. p. 121-166.

RIBEIRO JUNIOR, Nilo. Sabedoria da paz: ética e téo-lógica em Emmanuel Levinas. São Paulo: Loyola, 2008. 
SEBBAH, François-David. Lévinas. São Paulo: Estação Liberdade, 2009.

SOUZA, Ricardo Timm de. Levinas e a ancestralidade do mal: por uma crítica da violência biopolítica. Porto Alegre, EDIPUCRS, 2012. 